\title{
Topics of major current interest in scholarly editing and publishing based on the content analysis of selected journals
}

\author{
Yeonok Chung \\ Department of Social Welfare, Jangan University, Hwaseong, Korea
}

\begin{abstract}
For the purpose of obtaining a concrete picture of the main issues related to modern scholarly editing and publishing, a content analysis of the recent issues of three international journals devoted to scholarly editing and publishing, which are Learned Publishing, Journal of Scholarly Publishing, and European Science Editing, has been performed. The main topics in each of the 273 articles published in those journals over recent three years have been identified and classified into broad categories. The result has shown that the two most popular topics are open access publishing and peer review process. Other non-traditional topics currently receiving a great attention include bibliometrics, publication ethics, information technology applicable to editing and publishing, digital publishing, and literature databases. In order to keep up with the rapidly-developing field of scholarly editing and publishing and develop a local journal into an international journal of a high standard, it is important to remain keen to the latest development related to these topics.
\end{abstract}

Keywords

Content analysis; European Science Editing; Journal of Scholarly Publishing; Learned Publishing; Scholarly editing and publishing

Received: May 6, 2015

Accepted: August 7, 2015

Correspondence to Yeonok Chung yochung141@jangan.ac.kr

ORCID

Yeonok Chung

http://orcid.org/0000-0003-0008-5772

\section{Introduction}

The rapid spreading of the Internet and the development of advanced information technology have caused profound changes in many sectors of the human society. Nowadays, the ways scholars are collecting the information and conducting their researches and the processes of editing and publishing scholarly journals are vastly different from those of 20 years ago [1]. The number of scholarly journals, many of which are on-line and open-access journals, has increased sharply in recent years. Increasing use of technological advances, such as Internet search engines, electronic journal databases, Journal Article Tag Suite (JATS) extensible markup language (XML), and CrossCheck, is also changing the trends in journal editing and publishing 
[2].

Due to these advances, the issues confronting authors, editors, reviewers, publishers, librarians, and readers nowadays are diverse and complex, including publication ethics, peer review processes, journal metrics, and publication softwares. In order to obtain a more concrete picture of the main issues related to modern scholarly publishing, I have investigated the contents of the recent issues of three international journals devoted to scholarly editing and publishing, which are Learned Publishing (LP), Journal of Scholarly Publishing (JSP), and European Science Editing (ESE). I have identified the main topics in each of the over 270 articles published in those journals over recent three years and classified them into broad categories. The result has shown that the two most popular topics are open access publishing and peer review process. Other popular topics include bibliometrics and publication ethics.

\section{Methods}

For the purpose of grasping the main issues in contemporary scholarly editing and publishing, I have selected three journals devoted to the broad areas of editing and publishing, which are LP, JSP, and ESE. All of these journals are published four times a year. LP is published by the Association of Learned and Professional Society Publishers (ALPSP). Its authors are mainly professionals from the publishing houses and related service organizations. I have analyzed all articles published in volumes 24 , 25, and 26 from 2011 to 2013, except for book reviews. The total number of articles analyzed was 120. JSP is published by the University of Toronto Press. University professors, researchers, and librarians are among the main contributors. I have analyzed all articles in volumes 43,44, and 45 published from October, 2011 to July, 2014, except for book reviews. The total number of articles analyzed was 67 . Finally, ESE is published by the European Association of Science Editors (EASE). Editors and manuscript editors of scientific and medical journals are among the main contributors. I have analyzed all articles published in volumes 37, 38, and 39 from 2011 to 2013, except for book reviews and meeting reports. The total number of articles analyzed was 86.

For the combined total of 273 articles, I have examined carefully their abstracts, keywords, and main sections and classified their main topics into some broad categories. The classification categories were selected by referring to the aims and scope sections of these and other related journals. The list includes the topics such as policy of journal editing, data mining, research ethics, publication ethics, authorship, legal issues in journal publishing, peer review process, scientific literature databases, information technology applicable to journal editing and publishing, international standards of journal editing and publishing, reference styles, digital publishing and ebooks, education and training of editors, reviewers, and authors, manuscript editing, journal evaluation, bibliometrics and scientometrics, finance and business management of journal publishing, history of publishing, copyright and Creative Commons License, and open access publishing among many other things. For 256 articles, I have chosen one topic that represents the main content of each article most closely. For 17 articles, I have chosen two topics to represent the main content. For example, if an article is about the current situation of open access publishing in China, then I have assigned the article to two categories, namely open access publishing and editing and publishing in China.

\section{Results}

The results of the content analysis are summarized in four tables. In Table 1, I show the results of the analysis of the 120 articles published in LP. Seven articles were assigned to two topics, therefore the total number of articles appearing in the ta-

Table 1. Classification of 120 articles published in volumes 24,25 , and 26 of Learned Publishing according to main topics

\begin{tabular}{lc}
\hline Topic & No. of articles \\
\hline Open access publishing & 20 \\
Editing and publishing in China & 12 \\
Peer review process & 11 \\
Information technology applicable to editing and publishing & 10 \\
Finance and business management of publishing & 8 \\
Bibliometrics, scientometrics & 6 \\
Publication ethics, research ethics & 6 \\
Writing and submitting scientific manuscripts & 6 \\
Scientific literature databases & 6 \\
Journal usage statistics & 4 \\
Digital publishing, e-books & 4 \\
Information gathering pattern & 4 \\
Reference styles & 2 \\
Manuscript editing & 20 \\
Copyright, Creative Commons License & 127 \\
Learned association & 2 \\
Library management & 2 \\
Miscellaneous & 2 \\
Total & 2 \\
\hline
\end{tabular}

The total number appearing in the table is 127 instead of 120 because seven articles were assigned to two topics. 
ble is 127 instead of 120 . The most popular topic in LP is open access publishing. There are 20 articles devoted to it, consisting $16.7 \%$ of the total 120 articles. Twelve articles consisting $10 \%$ of the total are on scholarly editing and publishing in China. It seems that the international publishing industry is greatly interested in the emerging Chinese publishing market. New directions in the peer review process and various kinds of advanced information technology applicable to journal editing and publishing are also generating a lot of interest. Other topics of wide interest include finance and business management of publishing, bibliometrics and scientometrics, publication ethics and research ethics, writing and submitting scientific manuscripts, and scientific literature databases. Multiple articles are also devoted to journal usage statistics, digital publishing and e-books, and information gathering patterns in the Internet age.

Next, in Table 2, I show the results of the analysis of the 67 articles published in JSP. Six articles were assigned to two topics, therefore the total number of articles appearing in the table is 73 instead of 67. The most popular topic in JSP is peer review process. There are 7 articles devoted to it, consisting $10.4 \%$ of the total 67 articles. In addition, topics such as digital publishing and e-books, open access publishing, history of publishing, finance and business management of publishing, and traditional publishing are covered by many articles. Mul-

Table 2. Classification of 67 articles published in volumes 43,44 , and 45 of Journal of Scholarly Publishing according to main topics

\begin{tabular}{lc}
\hline Topic & No. of articles \\
\hline Peer review process & 7 \\
Digital publishing, e-books & 6 \\
Open access publishing & 5 \\
History of publishing & 5 \\
Finance and business management of publishing & 5 \\
Traditional publishing & 5 \\
Editing and publishing in China & 4 \\
Writing and submitting scientific manuscripts & 4 \\
Bibliometrics, scientometrics & 3 \\
Reference styles & 3 \\
Library management & 3 \\
Scientific literature databases & 2 \\
Authorship & 2 \\
Miscellaneous & 19 \\
Total & 73 \\
\hline
\end{tabular}

The total number appearing in the table is 73 because six articles were assigned to two topics. tiple articles are also devoted to editing and publishing in China, writing and submitting scientific manuscripts, bibliometrics and scientometrics, reference styles, and library management. Characteristically, this journal has many articles related to humanities and social sciences.

In Table 3, I show the results of the analysis of the 86 articles published in ESE. Four articles were assigned to two topics, therefore the total number of articles appearing in the table is 90 instead of 86 . There are 15 articles, which consist $17.4 \%$ of the total 86 articles, devoted to writing skills and the issues related to writing and submitting scientific manuscripts to journals. The second most popular topic is bibliometrics and scientometrics. Tweleve articles on this topic consist $14 \%$ of the total. Topics such as peer review process, publication ethics, open access publishing, authorship, and policy of journal editing are also covered by many articles. In general, ESE deals with many issues faced by editors and manuscript editors of scientific journals.

Finally, in Table 4, I combine the results of the analysis of the 273 articles published in all three journals. Seventeen articles were assigned to two topics, therefore the total number of articles appearing in the table is 290 instead of 273 . Since the three journals analyzed have an emphasis on different and complementary aspects of scholarly editing and publishing, the combined data appear to give a rather balanced view of the important issues in the field. The two most popular topics are open

Table 3. Classification of 86 articles published in volumes 37, 38, and 39 of European Science Editing according to main topics

\begin{tabular}{lc}
\hline Topic & No. of articles \\
\hline Writing and submitting scientific manuscripts & 15 \\
Bibliometrics, scientometrics & 12 \\
Peer review process & 8 \\
Publication ethics & 8 \\
Open access publishing & 8 \\
Authorship & 5 \\
Policy of journal editing & 5 \\
Manuscript editing & 4 \\
Editing and publishing in Iran & 3 \\
Reference styles & 2 \\
Editing and publishing in Russia & 2 \\
Editing and publishing in Estonia & 2 \\
Miscellaneous & 16 \\
Total & 90 \\
\hline
\end{tabular}

The total number appearing in the table is 90 because four articles were assigned to two topics. 
Table 4. Classification of 273 articles published in three recent volumes of Learned Publishing, Journal of Scholarly Publishing and European Science Editing according to main topics

\begin{tabular}{lc}
\hline Topic & No. of articles \\
\hline Open access publishing & 33 \\
Peer review process & 26 \\
Writing and submitting scientific manuscripts & 25 \\
Bibliometrics, scientometrics & 21 \\
Editing and publishing in China & 16 \\
Publication ethics, research ethics & 14 \\
Finance and business management of publishing & 13 \\
Information technology applicable to editing and publishing & 11 \\
Digital publishing, e-books & 10 \\
Scientific literature databases & 9 \\
Authorship & 8 \\
Reference styles & 7 \\
Policy of journal editing & 7 \\
History of publishing & 6 \\
Manuscript editing & 690 \\
Traditional publishing & 6 \\
Library management & 6 \\
Journal usage statistics & 6 \\
Information gathering pattern & 6 \\
Miscellaneous & 5 \\
Total & 4 \\
\hline & \\
\hline
\end{tabular}

The total number appearing in the table is 290 instead of 273 because seventeen articles were assigned to two topics.

access publishing and peer review process, which consist $12.1 \%$ and $9.5 \%$ of the total 273 articles respectively. Writing and submitting scientific manuscripts and bibliometrics and scientometrics are also very popular topics. Other important topics covered by many articles include editing and publishing in China, publication ethics and research ethics, finance and business management of publishing, information technology applicable to editing and publishing, digital publishing and ebooks, scientific literature databases, and authorship.

\section{Discussion}

In this article, I have analyzed the contents of articles published in three recent volumes of LP, JSP, and ESE. By carefully classifying all 273 articles published during that period into selected broad categories, I have figured out the topics of major current interest in scholarly editing and publishing. It has been found that open access publishing and peer review process are the two hottest topics in the field. Other non-traditional topics currently receiving a great attention include bibliometrics, publication ethics, information technology, digital publishing, and literature databases. In order to keep up with the rapidly-developing field of scholarly editing and publishing and develop a local journal into an international journal of a high standard, it is important to remain keen to the latest development related to these topics.

\section{Conflict of Interest}

No potential conflict of interest relevant to this article was reported.

\section{References}

1. Smart P. The big picture: scholarly publishing trends 2014 . Sci Ed 2014;1:52-7. http://dx.doi.org/10.6087/kcse.2014.1.52

2. Huh S. Journal Article Tag Suite 1.0: National Information Standards Organization standard of journal extensible markup language. Sci Ed 2014;1:99-104. http://dx.doi. org/10.6087/kcse.2014.1.99 